\title{
Living labs - instruments of social innovation in rural areas
}

\author{
Andreea-Maria Tirziu ${ }^{1}$ and Catalin Vrabie ${ }^{2}$
}

\begin{abstract}
In a country where nearly half the population lives in rural areas, it is difficult to link concepts such as smart cities, Internet of Things to the local government's priority list. However, lately there have been numerous initiatives to improve access to information using ICT in the rural communities as well. The purpose of this article is not to exhaustively measure the already adopted means, but merely to provide a series of items retrieved as barriers to ICT projects meant to develop these communities. Following the studies conducted so far (in Romania there are about 2,700 communes - the lowest administrative entities of our country), it was observed that the digital divide is found in 100\% of these areas. At the urban level - especially in the big cities, pilot projects for developing digital literacy among the elder population had a relatively high success. Such programs have been initiated at the level of the communes whose living standard is higher (the ones that are located near large cities). Their successes, though certainly less visible than in the urban communities, are noteworthy. Most such programs have targeted educational and health fields. The article we propose aims to show these programs' implementation degree in Romania, providing as examples the most successful cases that help the social innovation process. The intention with which we start this study is to create a list of objectives that the initiators of these programs have to take into account during the preparation of those programs.
\end{abstract}

\section{Introduction}

Two elements that, over time, have brought significant improvements regarding the modality in which individuals in a society can have access to the services provided by the public administration are computers and, undoubtedly, the Internet [1].

The new digital era is represented by a transition process, therefore the industrial society is transformed into a new type of society, namely the information one [29]. In such a society, information is accessed, processed, stored and sent in a more cheap, quick and easy manner, existing industries are being modified and new ones are being created, thus appearing major effects on citizens [29]. Therefore information society represents a natural extension of the democratic society, which requires information of public interest to operate, being characterized by a high level of data use by citizens in everyday life, in the majority of organizations and institutions [15]. This kind of society uses technology common or compatible with a wide range of personal, social, educational and business activities, while having the ability to rapidly receive and transmit digital data between parties of the process, regardless of the distance at which they are situated [15].

Modern societies rely more and more on digital technologies, therefore it becomes obvious that these technologies impose social changes in order to be successfully used for the communities' benefit. These social changes can be understood as changes in the current way of living, derived from changing the life conditions, the cultural equipment, the population composition or even the

\footnotetext{
${ }^{1}$ SNSPA, Bucharest, Romania, e-mail: tirziu.andreea@yahoo.com

${ }^{2}$ SNSPA, Bucharest, Romania, e-mail: cataloi@yahoo.com
} 
ideologies, whether appeared as a result of individuals' changes in a group or of the inventions created by them [25].

All around the world, social innovation is seen as the main goal for human development. Over time, the concept was shaped by researchers in order to capture the new technological trends and to provide to policymakers information and mechanisms that will help to add value to the society. Unfortunately, nowadays, while the challenges are growing, the budgets stay limited. For dealing with this situation, "policy labs" have been created which, "through their user-centred design thinking and experimental approaches", can be an instrument of social innovation. Public policy labs are considered to be entities structurally linked to public authorities, that use user-centred and experimental design methods in order to support the policy making and innovation processes which take place in the public sector [35].

In this regard, the European Commission has generated its own EU Policy Lab that, with the help of the European Parliament, has developed a project with the purpose to connect local, regional or national policy labs to the policy departments within the European Commission. This initiative started in June 2014 under the recommendations of the Expert Group on Public Sector Innovation and, moreover, an important event for its achievement was LAB CONNECTIONS, a policy labs meeting of European countries, held on October 17-18, 2016. This gathering had the aim to create a space open for collaboration between policy labs and policymakers at local, regional, national and EU level, addressing policy challenges and trying to identify actions that could solve social problems and find methods to get those actions started [35]. The policy challenges addressed were: 1) connecting digital, physical, natural and social solutions for cities; 2) culture and creative sectors in youth employment; 3 ) improve practice and policy for youth employment; 4) against segregation in mainstream education; 5) address public perception on migration; 6) mobilize employers for integration of refugees; 7) assist European start-ups; 8) a EU-wide once-only principle; 9) a citizen charter for digital public service; 10) future skills for healthcare professionals [35].

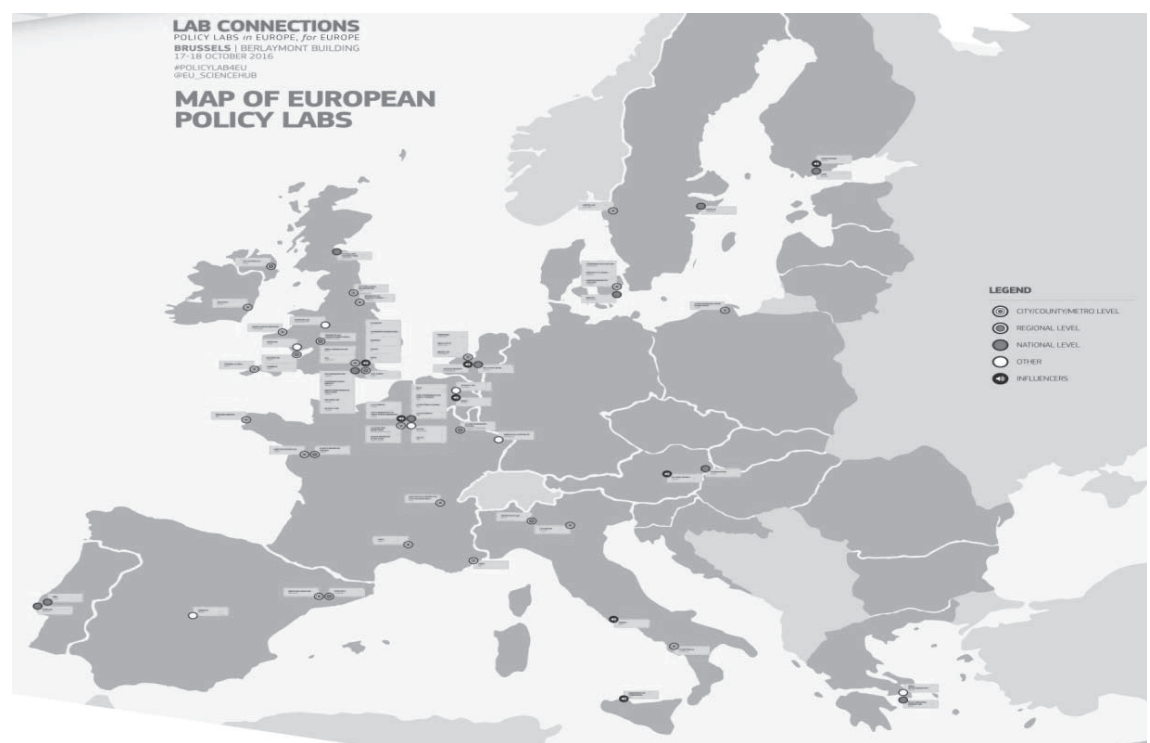

Figure. 1: Map of European policy labs [17] 
As we can see from the figure above, Romania has no involvement yet in this project, this putting Romanian urban and rural communities many steps behind the European countries that have understood the importance of having at least one policy lab that can help them generate innovative ideas and put into motion actions which will solve the social challenges that information-based communities raise today.

Although the challenges discussed within the LAB CONNECTIONS project are addressed to cities, they can be of great interest to policymakers for solving social problems of rural areas ${ }^{3}$ too and many successful activities are presented on the project's official webpage. Depending on the successful achievement of those activities, this European project can show a new way of connecting, discussing and working with citizens and other actors involved in the process ${ }^{4}$. It can also bring an important contribution regarding the implementation of more relevant and effective EU policies, also helping the EU member states better connect and communicate with their citizens [35].

Moreover, for stronger local policy labs, the NGOs can also be included amongst the interested parties of the process. They can have an important role in opting for various projects that, by providing an experimental approach, can produce visions and results of great value. In other words, NGOs can take the role of supporting the formulation and shaping of new policy initiatives, they can implement new actions for the already established policies and evaluate the existing policies. These organizations can also generate possibilities of consolidating relationships that already exist within the policy lab managers' network, by making the established projects more visible and credible and by offering instruments needed for developing the initial initiatives [12].

\section{Social innovation in rural areas}

Social innovation is considered to be a concept that "stimulates people, politicians and policy makers to explore and implement new ideas about the way how a society deals with several challenges, such as the increasing ageing of the population, the financial and economic crises, the quality of educational system or the regeneration of socially and economically deprived cities and regions" [21].

When referring to a living lab, the stakeholders of the innovation process (between which a strong interrelationship should exist) are: the companies - which can get new and innovative ideas; the users - which can get the innovation they want/need; the public organizations - which can get greater return on investment regarding the innovation research; and researchers - which can find and share important information on successful study cases [27].

In this context, the actors involved in the social innovation development process represent a very important element, the figure below presenting the role of different actors.

\footnotetext{
${ }^{3}$ A rural area is an open land field with few homes or other buildings, and fewer people than the urban areas [34].

${ }^{4}$ We can understand that the target groups of living labs are mainly: the users (citizens and community); the SMEs (including micro-entrepreneurs as providers); the larger companies; the research actors, the economy and the society[9].
} 


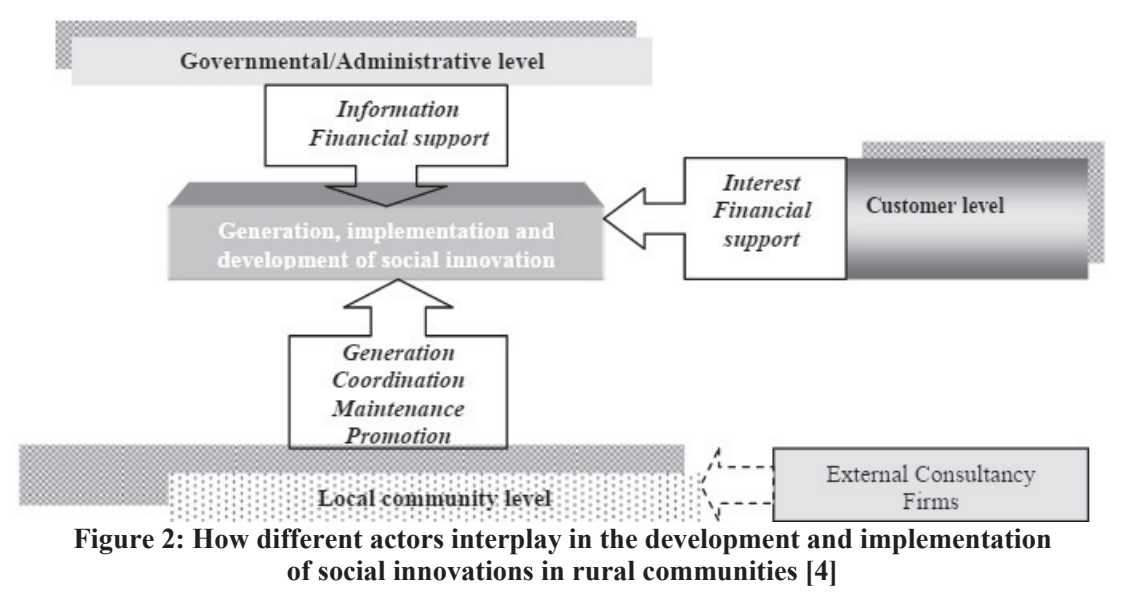

Figure 2 highlights the fact that, at a local level, there are various forms of social partnerships in order to produce social innovations. Moreover, experts in the field explain that these innovations are implemented in order to support certain ways of development regarding the rural communities or to moderate the negative consequences that may appear when processes are being restructured. Social innovation is believed to be a new concept for rural residents and communities because there are used new methods of development, common actions that can help facilitate the achievement of main objectives, new types of activities that use new forms of organization [4].

In urban and also rural areas, lifestyle changes request and determine innovations [3]. Apart from focusing on ideas, social innovations should concentrate on finding the proper methods to arrange those ideas that sometimes are not even new ones. When ideas are re-shaped in a new way, new quality is obtained from the products or services developed. In this case, it is social innovation the one that makes many changes [4].

There have been set up some elements of social innovation that could serve as instruments regarding process restructuring in rural areas and these are the following: a) new services in rural settlements - for e.g., the local communities should carry out actions that lead to the rural tourism development; b) new education courses for rural people - the main focus is on developing computer literacy ${ }^{5}$; c) ecological farming - a substantial element in restructuring process at a rural level in periods of change; d) formation of local action groups - these can create projects and strategies useful for local development and they can also propose the implementation of various social innovations; f) electronic social innovations - for e.g., local authorities can create for their communities [4].

Apart from the elements mentioned before, social innovation in rural areas tries to carry on objectives, such as: a) the change in attitudes - the most relevant social innovation should be related to this and it should be directed towards following the "bottom up" principle and common ideas; b) consolidation and community development - new things should be created together, by the individuals, and efficiency and profit should be aimed at in order to change the lives of people who live in rural areas; also there should be a mobilization regarding community actions; c) new knowledge - educational potential can help in making profit, therefore it is an essential aspect to

\footnotetext{
${ }^{5}$ The ability to use computers and related technology efficiently, with a range of skills covering levels from elementary use to programming and advanced problem solving [36].
} 
make use of it; d) environmental protection, new organizational forms and improvement of life quality - these are aspects that should be taken into consideration, especially for helping the process of improving life quality, the community coming with very big expectations regarding this issue [4].

We can easily see that the main actor in developing social innovation in rural areas is the community, the human resource, therefore the successful carrying out of social innovations depends very much on the characteristics of the respective community. The actors involved in the process from a national level should carry out top-down initiatives in order to ease the activities based on a bottom-up approach [4]. Social change is a fundamental purpose of the innovation process, therefore social innovations are considered to be both the wanted outcome and the tool and approach that, through engaging the communities, will help rescue rural societies [3]. For this purpose to be met, the population must be organized and educated in such a manner that it achieves the capability and willingness to engage and re-create the society it forms, and also finding solutions against the barriers that intervene in the change process, by forming influential lobbies for local interest [6].

\section{Connection between living labs, ICT and social innovation}

The connection between these three concepts can be easily understood by defining the living labs, which are open innovation ecosystems, centered on users and based on an approach that will make the users be co-creators regarding research and innovation processes in real life communities and locations. The citizen is therefore positioned at the center of innovation, these labs having the ability to better make use of the opportunities made accessible by the new ICT concepts and solutions that are being found in order to meet specific needs and desires that local cultures, settings and creativity potentials rise [11].

In this context, The European Network of Living Labs (ENoLL) is a relevant example of how important the connection between living labs, ICT and social innovation is. Founded in 2006, ENoLL is the international federation of benchmarked living labs at European and global level. Today, it counts more than 170 active living labs worldwide, providing to its members co-creation, user engagement, test and experimentation services, having as a main target innovation in various fields of activity. This not for profit association acts as a platform for exchanging best practice cases, learning and support and also for the development of the living lab international project [11]. 


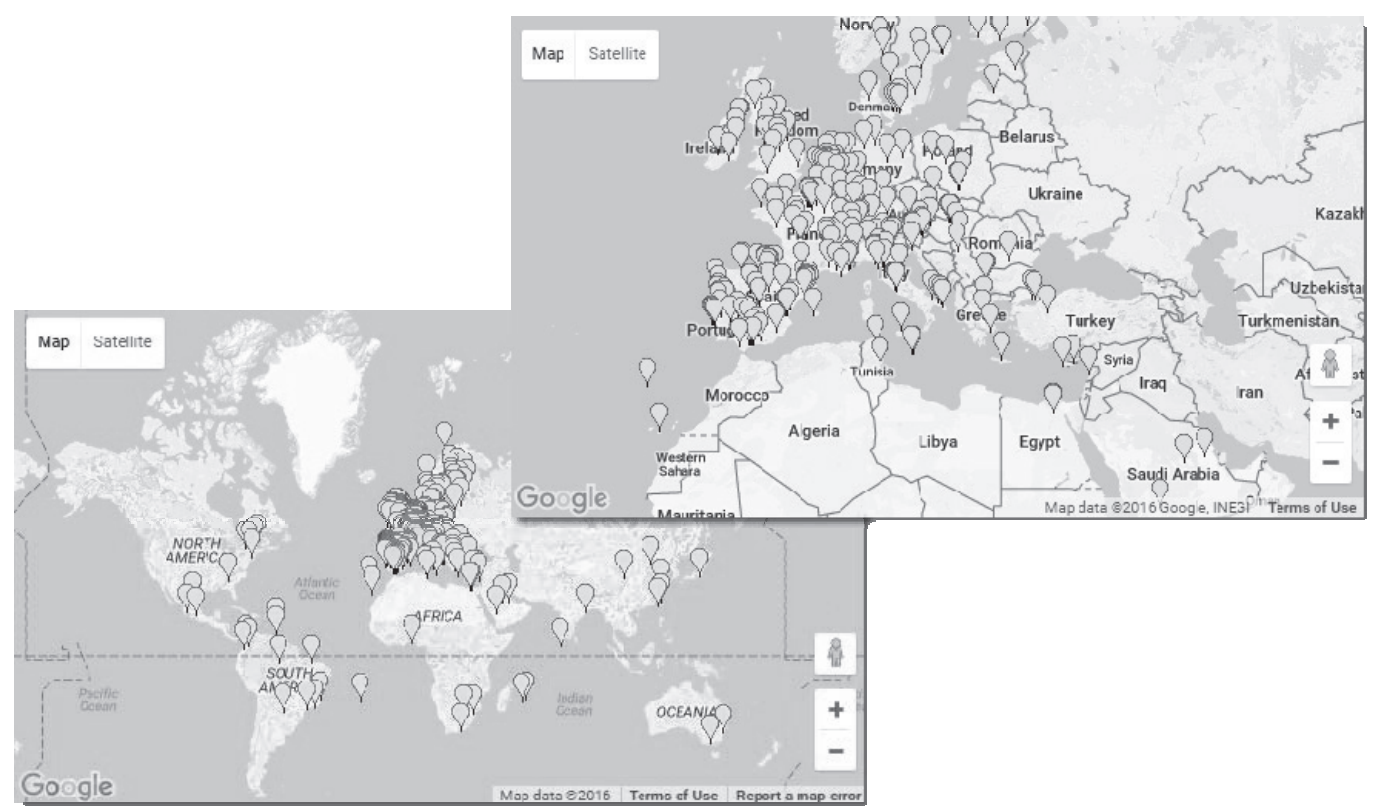

Figure. 3: Living Labs in ENoLL member states [11]

As it can be found on ENoLL's website, Romania is an adherent member and it had a living lab (in Bucharest) named A.R.C.H.E.S ${ }^{6}$. This was launched by University Politehnica Bucharest with the purpose to create, for the first time in Romania, a platform oriented on synergy. Moreover, SIG-RO (a special interest group in Romania) focusing on multi-disciplinary academic research, established ARCHE3S ${ }^{7}$ - the Bucharest metropolis-oriented living lab [28].

The contents of this project are sustained by the following elements: 1) rigorous selection of the high-priority complex problems to be solved along their life-cycle - case studies: a) National Remedy project no. 138 (2006-2007) which had the aim to observe the pollutants effects on health; b) In-Tech-Transfer - technology transfer from academic research towards Romanian SMEs within the RELANSIN ${ }^{8}$ national programme (2004-2012); 2) interoperability-focused complex problem to support e-democracy, e-government and policy making - Leverage FP7-Strep proposal ${ }^{9}$; 3) stimulate the young generations of students to develop an innovative thinking and have access to entrepreneurship education - e.g.: University Politehnica Bucharest department for lifelong learning in order to sustain the job selection on dynamic European work force market, Business Incubators at the same university etc.; 5) support the awareness of Romanian citizens living in Bucharest regarding the complex public services that are based on Internet use [28].

\footnotetext{
${ }^{6}$ This Living Lab is no longer an active member of the ENoLL network since 2010 [11].

7 ARCHE3S is described by the public-private initiative focused on: automation, robotics, computers, science, healthcare, energy, efficiency, environment sectorial activities, based on coherent, consistent and competitive system of systems approach [28].

${ }^{8}$ The purpose of this program is the economic re-launch of units, groups or categories of economic units, with Romanian majority capital, by implementing integrated projects covering both the research and development process, and the one of achieving the investment needed in order to obtain the expected economic results [19].

${ }^{9}$ STREP (Specific Targeted Research Projects) are multi-partner research, demonstration or innovation projects and their aim is to support activities of a more limited purpose and ambition than the large scale integrating collaborative projects (IPs) [10].
} 
The successful examples of urban living labs from around the world can also be of interest for Romanian local authorities in order to produce impact on rural development through the development of the rural innovation system, change of current rural policies, impact on business and entrepreneurship, on social and individual welfare and also impact on internationalization [24]. Moreover, the public administration plays an important role in enhancing the creation of innovations and the use of ICT for developing living labs and, thus, for increasing productivity, boosting the creation of public value, improving efficiency in the relationship between the citizens and the public authorities, meeting the challenges that today society raises [20].

\section{Barriers to ICT projects meant to develop rural areas}

Research on rural areas has shown that increasing the possibility to access ICT and their applications has become an important policy issue for the future development of those rural regions. This also brings benefits for the citizens, firms and rural communities, ICT having the potential to develop an open digital platform that will make effective and efficient interaction possible, thus gathering intelligence in a unique place. They can also help both the macro level (represented by the rural areas) and the micro level (constituted by individuals and companies) to boost their competitive position in the new economy context [30].

Regarding the barriers that intervene in the development of ICT projects meant to boost the development process of rural areas, we can see that there are various categories that need to be taken into consideration [30]:

a) Barriers related to the network infrastructure organization: costs for the deployment of the infrastructure, lack of sufficient demand [14]; diversity of ICT applications which can meet the needs of rural communities and the requirements related to the network infrastructure; lack of continuous and high speed network connections;

b) Barriers related to the development of specific ICT applications and content: rural areas may lack of access to proper equipment necessary for the development of specific applications, costs involved; lack of knowledge regarding the range of applications, lack of regionallyfocused and demand-driven approach to categorize various needs; costs for the content development [23]; applications and content developers may not have knowledge on the regions' specifics and their needs; obstacles regarding the management of digital content;

c) Barriers related to the adoption and use of technology by end-users: lack of skilled human resource; lack of institutional capacity; limited range of e-government services that use open IT standards; low level of entrepreneurship; lack of training opportunities; lack of new technology culture etc.;

d) Barriers related to limited or missing capacity of network infrastructure in regard to the type of applications or the content that could meet the needs of rural areas: lack of region-specific and demand-driven approach to network infrastructure and ICT applications; multiplicity of network requirements specific to applications in rural areas;

e) Barriers related to the type of network infrastructure chosen for supporting e-apps in rural context: the type of network infrastructure technology should be in compliance with the rural communication design [13]; lack of establishment of multi-devices or multi-channel access 
[16]; behavior of local population; costs regarding the network infrastructure use; costs for getting access to the equipment needed for joining the network;

f) Barriers related to the type of apps and content specific for different types of end-users: lack of user-oriented knowledge development; lack of efficient interaction between researchers as developers of ICT apps and end-users [23]; lack of users' involvement in the apps' design or content [18]; non user-friendly apps; lack of multi-channel digital communication system for integrating all media [16]; costs regarding the access or use of the ICT apps and content.

Apart from these constrains, the digital divide should be mentioned. The overall potential of the EU is slowed down by a divide regarding innovation and, mostly, digital skills, along with heterogeneity in the enterprise environment [38]. In this regard, it would be very useful to create and put into motion national or even local projects meant to inform and train the population in order to be capable to use the new ICT, this process being called "digital literacy" [2][37].

Solving these problems could mean finding the objectives that need to be taken into consideration when the social innovation programs are being prepared, therefore policy and decision makers should pay attention to these issues and try to find the most effective and efficient manner to contribute to the development process of their local communities.

\section{Case study: successful programs that help the social innovation development process in rural areas}

\subsection{European case}

At the European level, there are two projects that we consider as being of great importance for our research, focusing on boosting social innovation in rural areas.

The first one is a project called SIMRA (Social Innovation in Marginalised Rural Areas) which is a four-year action period (2016-2020), being funded by the EU's Horizon 2020 programme. Its purpose is to improve the understanding of concepts such as social innovation and innovative governance in the forestry, agriculture and rural development fields and find methods to enhance them in marginalized rural areas from Europe and around the Mediterranean, including zones situated in states that are non-EU members [26]. This project's objectives will be carried out by realizing the following activities:

"1) Developing systematic frameworks: a) theoretical - for improved knowledge of the complexity of SIs and its dimensions, and its impact on unfolding territorial capital; b) operational - based on a trans-disciplinary coalition (researchers and practitioners) to advance understanding of preconditions and success factors for implementing/operationalizing SI;

2) Creating a categorisation of SIs which encompasses the specificities in terms of social priorities, relationships/collaborations etc. and serves as an instrument to explore reasons why regions with similar conditions display diverging paths and to 'turn diversity into strength';

3) Creating an integrated set of methods to evaluate SI and its impacts on economic, social, environmental, institutional and policy dimensions of territorial capital; 
4) Co-constructed evaluation of SIs in case studies across the spatial variation of European rural areas, considering which components of territorial capital foster and, or mainstream RD;

5) Synthesis and dissemination of new or improved knowledge of SIs and novel governance mechanisms to promote social capital and institutional capacity building and inform effective options/solutions for shaping sustainable development trajectories;

6) Creating collaborative learning and networking opportunities and launching innovative actions at different/multiple scales, with continuous interactions among researchers, "knowledge brokers' and stakeholders to foster and mainstream SI, leaving a durable legacy" [7].

Another European project example is RurInno, which is a project for which award-winning social enterprises and high-profile institutes from four EU states work together in the Horizon 2020 programme with the aim to boost rural development [22]. It "strives to enhance knowledge about social enterprise driven innovation processes and at the same time to utilise the insights to improve the ability of social enterprises to tackle social challenges in rural regions" [5].

\subsection{Romanian case}

While at the European level there is a strong interest in developing living labs as instruments of social innovation in rural areas, in Romania public authorities barely heard about this issue. Back in 2005, a project entitled eComunitate [eCommunity $]^{10}$ was developed, following the knowledge of the economy concept, under the auspices of the Ministry of Information Technology and Communications. The program's main objective was to connect all the communes in one single place on the Web in order to share knowledge and information for a better and cheaper interaction among the authorities [8]. Even though the project is ten years old already, not the entire rural community in Romania adhered to it.

The table below has the aim of presenting the activity of the most active communities which are members in the project "Economy based on Knowledge (EBK)"11. It shows the events, news and other interest subjects from the rural areas, shared through the eComunitate portal. One point is accorded for each material that comes from the community and covers local news or events and is of interest for the editorial team and two points for each item or success story that comes from the community and is of interest for the editorial team [8].

\footnotetext{
10 The eComunitate portal is an initiative launched within the project "Economy based on Knowledge" [8].

${ }^{11}$ The total no. of communities presented on the website is equal to 231 , but we chose to present the 10 most important ones based on the criteria researched and provided under the auspices of the project.
} 


\begin{tabular}{cccccccc} 
Position & Community & Project & Education & Business & Administration & Culture & Total \\
\hline $\mathbf{1 .}$ & Recas & 22 & 39 & 18 & 19 & 17 & $\mathbf{1 1 5}$ \\
$\mathbf{2 .}$ & Luncavița & 24 & 9 & 30 & 40 & 8 & $\mathbf{1 1 1}$ \\
$\mathbf{3 .}$ & $\underline{\text { Sângeorgiu de }}$ & 6 & 25 & 27 & 42 & 9 & $\mathbf{1 0 9}$ \\
& $\underline{\text { Pădure }}$ & & & & & & \\
$\mathbf{4 .}$ & $\underline{\text { Teiu }}$ & 7 & 79 & 6 & 6 & 8 & $\mathbf{1 0 6}$ \\
$\mathbf{5 .}$ & Homocea & 2 & 30 & 32 & 20 & 4 & $\mathbf{8 8}$ \\
$\mathbf{6 .}$ & Diosig & 6 & 24 & 25 & 25 & 2 & $\mathbf{8 2}$ \\
$\mathbf{7 .}$ & $\underline{\text { Târgu Frumos }}$ & 9 & 27 & 3 & 16 & 22 & $\mathbf{7 7}$ \\
$\mathbf{8 .}$ & Zlatna & 8 & 19 & 21 & 29 & 0 & $\mathbf{7 7}$ \\
$\mathbf{9 .}$ & Mircea Vodă & 7 & 18 & 11 & 25 & 8 & $\mathbf{6 9}$ \\
$\mathbf{1 0 .}$ & $\underline{\text { Saschiz }}$ & 6 & 5 & 15 & 26 & 15 & $\mathbf{6 7}$ \\
\hline
\end{tabular}

Table 1: Top ten EBK communities most active on the eComunitate portal [8]

\section{Conclusions}

By taking into consideration the living labs successful examples from all over the world, rural areas can become smarter communities, making use of ICT activities that will help them create social innovations and sustain development.

Social innovation is a practice that can be made possible through the process of creation. In this regard, we believe that ICT is very useful in making the individuals "think outside the box" and come up with ideas that can transform their communities. By that, they can be even more creative and they will become responsible citizens that will be able to find solutions for the society they live in [31].

For the benefit of citizens and rural small businesses, efficient electronic services must be developed. Therefore, the public institutions must embrace a more general approach, by evaluating the electronic services already in use and by creating new ones where and when they are needed [33].

However there must be remembered that, although electronic technologies provide important aid for social innovation and the improvement of the rural areas' well-functioning and development, the key factor in any interpersonal relationship remains the human resource, therefore the interaction between individuals should not be absolutely suppressed, but a balance must be found between the use of digital technologies and traditional methods in order to perform certain actions [32].

\section{References}

[1] BALTAC, V.: Information technologies - Basic notions, Andreco Educational, Bucharest, 2011.

[2] BALTAC, V.: Miths and reality in the digital world, Excel XXI Books, Bucharest, 2016.

[3] BOCK, B.: Social innovation and sustainability; how to disentangle the buzzword and its application in the field of agriculture and rural development, Studies in Agricultural Economics, no. 114, 2012.

[4] BUTKEVIČIENE, E.: Social Innovations in Rural Communities: Methodological Framework and Empirical Evidence, Social Sciences, no. 1 (63), 2009. 
[5] CHRISTMANN, G.: Personal communication from the deputy director of the Leibniz Institute for Research on Society and Space, Germany, RurInno project partner, RurInno website, http://rural-innovations.net/articles/2016/5/30/social-innovations-in-rural-regionslaunch-of-eu-horizon-2020-project, accessed on December 2016.

[6] CONVERY, I. et al.: Mainstreaming LEADER delivery of the RDR in Cumbria: an interpretative phenomenological analysis, Sociologia Ruralis, vol. 50, no. 4, 2010.

[7] CORDIS (Community Research and Development Information Service), http://cordis.europa. eu/project/rcn/200385_en.html, accessed on December 2016.

[8] ECOMUNITATE PORTAL, http://www.ecomunitate.ro/, accessed on December 2016.

[9] EUROPEAN COMMISSION - DIRECTORATE GENERAL FOR THE INFORMATION SOCIETY AND MEDIA, Living Labs for user-driven open innovation. An overview of the living labs methodology, activities and achievements, Office for Official Publications of the European Communities, Luxembourg, 2008.

[10] EUROPEAN COMMISION WEBSITE, http://cordis.europa.eu/fp7/ict/future-networks /funding-schemes_en.html, accessed on December 2016.

[11] EUROPEAN NETWORK OF LIVING LABS (ENoLL) WEBSITE, http://www.openliving labs.eu/aboutus, http://www.openlivinglabs.eu/ourlabs/Romania, accessed on December 2016.

[12] FUlLER, M. and LOCHARD, A.: Public policy labs in European Union Member States, EUR 28044 EN, Publications Office of the European Union, Luxembourg (2016).

[13] GOUSCOS, D., MENTZAS, G. and GEORGIADIS, P.: Planning and implementing eGovernment service delivery: achievements and learnings from on-line taxation in Greece, paper presented at the Workshop on e-Government, 8th Panhellenic Conference on Informatics, Nicosia, Cyprus, November 8-10 (2001), cited by STRATIGEA, A., ICTs for rural development: potential applications and barriers involved, Netcom, 25 -3/4, 2011.

[14] HAMMOND, A. and PAUL, J.: A new model for rural connectivity, World Resources Institute, Development Thought Enterprise (2006), cited by STRATIGEA, A., ICTs for rural development: potential applications and barriers involved, Netcom, 25 - 3/4, 2011.

[15] HELLAWELL, S.: The Net Result - Social Inclusion in the Information Society, Report of the National Working Party on Social Inclusion (INSINC), IBM United Kingdom Limited, London, 1997.

[16] KASTELLS, M.: The rise of the network society, the information age: economy, society and culture, Volume I, Wiley-Blackwell, West Sussex, UK (2010), cited by STRATIGEA, A., ICTs for rural development: potential applications and barriers involved, Netcom, $25-3 / 4$, 2011.

[17] LAB CONNECTIONS, http://blogs.ec.europa.eu/eupolicylab/lab-connections/, accessed on December 2016. 
[18] LIND, M. et al.: Integrated broadband development, use and learning in a co-design setting: case study e-Me infrastructure, BIRD Project - Broadband Access for Innovation and Regional Development, European Community, European Regional Development Fund (2008), cited by STRATIGEA, A., ICTs for rural development: potential applications and barriers involved, Netcom, $25-3 / 4,2011$.

[19] MANAGERIAL AGENCY FOR SCIENTIFIC RESEARCH, INNOVATION AND TECHNOLOGY TRANSFER (AMCSIT) - POLITEHNICA WEBSITE, http://www.amcsi t.ro/amcsit.old/relansin.html, accessed on December 2016.

[20] MATEI, A., SĂVULESCU, C. and ANTONOVICI, C.: Social Innovation in the Local Public Sector: A Cross-Regional Approach for Romania, Theoretical and Applied Economics, vol. 22, no. 4(605), 2015.

[21] MULGAN, J.: The art of public strategy, Oxford: Oxford University Press (2009), cited by MATEI, A., SĂVUlESCU, C., ANTONOVICI, C., Social Innovation in the Local Public Sector: A Cross-Regional Approach for Romania, Theoretical and Applied Economics, vol. 22, no. 4(605), 2015.

[22] RURINNO WEBSITE, http://rural-innovations.net/articles/2016/5/30/social-innovations-inrural-regions-launch-of-eu-horizon-2020-project, accessed on December 2016.

[23] SCAR FORESIGHT COMMITTEE (2007), FFRAF report: foresighting food, rural and agrifutures, Standing Committee for Agricultural Research, Version 20, February 2007, http://ec.europa.eu/research/agriculture/scar/pdf/foresighting_food_rural_and_agri_futures.pd f, cited by STRATIGEA, A., ICTs for rural development: potential applications and barriers involved, Netcom, 25 - 3/4, 2011.

[24] SCHAFFERS, H., MERZ, C. and GUZMAN, J.G.: Living Labs as Instruments for Business and Social Innovation in Rural Areas, work partly funded by the European Commission through IST Project C@R: Collaboration@Rural (No. IST-2006-34921), 2009.

[25] SHAH, S.: http://www.sociologydiscussion.com/sociology/theories-of-social-changemeaning-nature-and-processes/2364, accessed on December 2016.

[26] SIMRA (Social innovation in Marginalised Rural Areas), http://www.simra-h2020.eu/index. php/newsletter/, accessed on December 2016.

[27] STÅHLBRÖST, A. and HOLST, M.: The Living Lab Methodology Handbook, Social Informatics at Luleå University of Technology and CDT - Centre for Distance-spanning Technology, Sweden, 2012.

[28] STANESCU, A.M. et al: ARCHE3S: first Living Lab enabler in Romania aiming at cross domain synergy-based approach to sustain SMEs, University Politehnica Bucharest, 2015.

[29] STOICA, M.: Premises of transition to information society, Economic Information Journal, no. 4 (16), 2000. 
[30] STRATIGEA, A.: ICTs for rural development: potential applications and barriers involved, Netcom, $25-3 / 4,2011$.

[31] TIRZIU, A.M. and VRABIE, C.I.: NET Generation. Thinking outside the box by using online learning methods, New Trends and Issues Proceedings on Humanities and Social Sciences, issue 8, SPROC, 6th World Conference on Learning, Teaching and Educational Leadership (WCLTA 2015), October 29-31, 2015, Descartes University Paris, France, 2016.

[32] TIRZIU, A.M.: Social innovation - a beneficial vision on the public sector. Case study: social innovation in the public universities from Italy, vol. 3 of the "Smart Cities" Conference, 3rd edition, December 10, 2015, Pro Universitaria Publishing House, SNSPA, Bucharest, Romania, 2016.

[33] TIRZIU, A.M. and VRABIE, C.I.: Education 2.0: universities' e-learning methods, LAP Lambert Academic Publishing, Germany, 2015.

[34] TRADING ECONOMICS, http://www.tradingeconomics.com/romania/rural-populationpercent-of-total-population-wb-data.html, accessed on December, 2016.

[35] URBACT: http://www.blog.urbact.eu/2016/12/lab-connections-policy-labs-in-europe-foreurope-policylab4eu/, accessed on December 2016.

[36] U.S. CONGRESS - OFFICE OF TECHNOLOGY ASSESSMENT, Computerized Manufacturing Automation: Employment, Education, and the Workplace, Washington D.C., OTACIT-235, April 1984.

[37] VRABIE, C.: IT elements for the Public Administration, Pro Universitaria, 2nd edition, vol. 2, Bucharest, 2014.

[38] WORLD ECONOMIC FORUM, The Europe 2020 Competitiveness Report: Building a More Competitive Europe, Geneva, 2014. 